\title{
Analysis of Aloe vera cytotoxicity and genotoxicity associated with endodontic medication and laser photobiomodulation ${ }^{\text {th }}$
}

\author{
Nayane Chagas Carvalho ${ }^{\mathrm{a}, *}$, Simone Alves Garcez Guedes ${ }^{\mathrm{b}}$, \\ Maria Amália Gonzaga Ribeiro ${ }^{c}$ \\ a School of Dentistry of Pernambuco, University of Pernambuco, Camaragibe, Pernambuco, Brazil \\ b Tiradentes University, Sergipe, Brazil \\ ${ }^{\mathrm{c}}$ Federal University of Sergipe, Sergipe, Brazil \\ ' São Paulo State University - UNESP, São José dos Campos, São Paulo, Brazil
} Ricardo Luiz Cavalcanti Albuquerque-Júnior ${ }^{\mathrm{b}}$, Diana Santana de Albuquerque ${ }^{\mathrm{a}}$, Adriano Antunes de Souza Araújoc ${ }^{c}$, Luiz Renato Paranhos ${ }^{c}$, Samira Esteves Afonso Camargo ${ }^{\mathrm{d}}$,

\section{A R T I C L E I N F O}

\section{Keywords:}

Aloe vera

Cytotoxicity

Endodontic medication

Genotoxicity

Laser photobiomodulation

\begin{abstract}
A B S T R A C T
This study aims to evaluate, in vitro, the effect of Aloe vera associated with endodontic medication, with or without laser photobiomodulation (FTL) irradiation in FP6 human pulp fibroblasts. The materials were divided into eight groups: CTR - control; CL - FTL alone; AA - Aloe vera with distilled water; AL - Aloe vera with distilled water and FTL; HA - calcium hydroxide P.A. with distilled water; HL - calcium hydroxide P.A. with distilled water and FTL; HAA - calcium hydroxide P.A. with Aloe vera and distilled water; HAL - calcium hydroxide P.A. with Aloe vera, distilled water, and FTL. The cytotoxicity was evaluated by MTT assay at 24,48 , and $72 \mathrm{~h}$ and the genotoxicity by micronucleus test assay. This study was performed in triplicate. Data obtained in both tests were statistically analyzed by ANOVA and Tukey's tests $(p \leq 0.05)$. Group AA presented high genotoxicity and low cytotoxicity. After 24,48 , and $72 \mathrm{~h}$, the group HAA significantly reduced the cell viability. Interaction with FTL showed slightly increase cell viability after 24 and $48 \mathrm{~h}$ in groups CL and HL $(p<0.001)$, despite the high genotoxicity in group CL and low genotoxicity in group HL. Group AL showed higher cell survival rate at $72 \mathrm{~h}$ $(p<0.05)$ and high genotoxicity $(p<0.001)$. It was concluded that Aloe vera allowed higher cell viability in human pulp fibroblasts in the presence of calcium hydroxide or with FTL separately, but genotoxicity increased in these associations.
\end{abstract}

\section{Introduction}

The main objectives of root canal therapy are removal of pathologic pulp, cleaning, disinfection of contaminated root canals, shaping and obturation of the root canal system in three dimensions to prevent reinfection [1]. Hence, the professionals must know the complexity of the root canal system (RCS) of teeth with apical periodontitis and periapical radiolucency, to choose the better technical in these cases, to associate substances and medications that disinfect dentinal tubules, and to promote repair of periapical tissues [2].

The presence of microorganisms in areas with a difficult instrument access such as isthmus, ramifications, lateral canals, apical accessories and delta canals, and deep into dentinal tubules can interfere in the reparation process, thus requiring medication in between sessions to reach these areas [3].

Calcium hydroxide, antiseptics, and antibiotics are the most used medications in endodontic practice [4]. These medications can eliminate bacteria that survival to biomechanical preparation, reduce periradicular inflammation, neutralize toxic products, and stimulate repair by mineralized tissue [5].

Cytotoxicity is a destructive effect of some material on the cells [6], and genotoxicity is a detection of genetic material damages such as DNA and chromosome breakage, genetic mutation, and change in the repair ability of DNA [7]. In order to justify its applicability, intracanal medication should present high antimicrobial activity and low cytotoxicity and genotoxicity, aiming to achieve a potential for eliminating bacteria without damaging periapical tissues $[8,9]$.

Laser photobiomodulation is another resource used in dental

\footnotetext{
is Conflicts of interest: none.

* Corresponding author at: Rua Doutor Celso Oliva, n 321, Edf Saint Honoré, apt 101, 13 de Julho, Aracaju, Sergipe 49020-090, Brazil.

E-mail address: nayanecc@gmail.com (N.C. Carvalho).
} 
practice, acting as analgesic, anti-inflammatory, anti-edematous, and helping the tissue repair process [10]. The mechanisms of laser therapy irradiation include an increase of local microcirculation, angiogenesis, vasodilation, and inhibition of inflammatory mediators such as prostaglandins. Laser irradiation can avoid initiating the arachidonic acid cascade on damaged tissues, decreasing prostaglandin production [11].

It has been performed studies of new natural products with repair abilities aiming to support and accelerate the endodontic treatment in teeth with apical periodontitis and periapical radiolucency. The Aloe vera plant popularly known as "babosa" features among these products, keeping interesting properties to endodontic [12] such as anti-inflammatory and antibacterial action, as well as tissue repair stimulation [13]. Therefore, this study aims to analyze the cytotoxicity and genotoxicity of Aloe vera associated with endodontic medication with or without laser photobiomodulation irradiation in human pulp fibroblasts at 24,48 , and $72 \mathrm{~h}$.

\section{Materials and Methods}

The entire research method was performed according to the guidelines of the International Organization for Standardization (ISO) 10993-5:2009 [14] and in triplicate. The cell bank of the Laboratory of Cell Biology of the São Paulo State University (UNESP), Campus São José, Brazil, provided the human pulp fibroblasts (FP6) lineage used in the research.

\subsection{Division of Experimental Groups}

The intracanal medication used was calcium hydroxide P.A (Biodinâmica Química e Farmacêutica LTDA, PR, Brazil) associated with Aloe vera, with or without laser photobiomodulation irradiation. The vehicle selected for this experiment was distilled water (Eurofarma Laboratorios LTDA, SP, Brazil), due to its biologically inactive property. Table 1 shows the groups description and the concentrations of the intracanal medications used in this study.

FTL: $\uparrow$ laser photobiomodulation.

\subsection{Preparation of Extracts}

The Aloe vera leaves were obtained in the state of Sergipe, identified by voucher number ASE-37.261. A parenchyma scraping provided the gel, which was filtered, stored in sterile collector, wrapped in plastic film, and kept between $-18^{\circ}$ to $-25^{\circ}$ until freezing. Then, the sample was lyophilized. The Aloe vera pastes were manipulated in sterile

Table 1

Description of groups and the concentrations of the intracanal medications.

\begin{tabular}{lll}
\hline Groups & Substances & Concentrations \\
\hline CTR [Control) & Fibroblast culture medium & $200 \mu \mathrm{L} /$ well \\
CL & $\begin{array}{l}\text { FTL } \dagger \\
\text { Aloe vera } \\
\text { DA }\end{array}$ & $\begin{array}{l}\text { Distilled water } \\
\text { Aloe vera }\end{array}$ \\
AL & Distilled water & $4 \%$ \\
& FTL $\dagger$ & $4 \%$ \\
Calcium hydroxide P.A. & \\
HA & Distilled water & $90.9 \%$ \\
Calcium hydroxide P.A. & Distilled water & $90.9 \%$ \\
& FTL $\dagger$ \\
Calcium hydroxide P.A. & \\
HAA & Aloe vera & $16.39 \%$ \\
& Distilled water & $3.27 \%$ \\
Calcium hydroxide P.A. & $16.39 \%$ \\
HAL & Aloe vera & $3.27 \%$ \\
& Distilled water & \\
& FTL $\dagger$ & \\
& & \\
\hline
\end{tabular}

Table 2

Irradiation parameters for groups $\mathrm{CL}, \mathrm{AL}, \mathrm{HL}$, and $\mathrm{HAL}$.

\begin{tabular}{ll}
\hline Irradiation parameters & \\
\hline Emission mode (CW) & Continuous \\
Length & $\Lambda 660 \mathrm{~nm}$ \\
Active medium & InGaAlP \\
Laser optical power (output) & $10 \mathrm{~mW}$ \\
Laser optical power [(nput) & $40 \mathrm{~mW}$ \\
Beam area & $4 \mathrm{~mm}^{2}$ \\
Power density (PD) & $1 \mathrm{~mW}^{2} \mathrm{~cm}^{2}$ \\
Energy density (ED) & $3 \mathrm{~J} / \mathrm{cm}^{2}$ \\
Irradiation time (by session) & $3 \mathrm{~s}$ \\
Total energy per session (by well) & $0.12 \mathrm{~J}$ \\
Beam divergence perpendicular to the junction & $17^{\circ}$ \\
Tip angle & $50^{\circ}$ \\
\hline
\end{tabular}

Becker, stored in Falcon tubes protected with aluminum paper, and maintained at room temperature for $24 \mathrm{~h}$. The same tube received $5 \mathrm{~mL}$ of DMEM culture medium supplemented with $10 \%$ SBF and penicillin/ streptomycin; and incubated in $5 \% \mathrm{CO}_{2}$ at $37^{\circ} \mathrm{C}$, for $24 \mathrm{~h}$.

The specimens were produced with standardized shape and volume for all groups. Hence, the pastes were inserted in 5-mm diameter and 2mm thick sterile polyethylene tubes [14]. A humid atmosphere conditioned the calcium hydroxide pastes at $37^{\circ} \mathrm{C}$ with $5 \% \mathrm{CO}_{2}$ for $24 \mathrm{~h}$ so that all specimens would begin setting. After this period, still inside the polyethylene tubes, the medication was sterilized by ultraviolet radiation in the laminar flow chamber for $1 \mathrm{~h}$ to avoid contamination [15]. The Eppendorf tubes received $1 \mathrm{~mL}$ of DMEM culture medium supplemented with $10 \% \mathrm{SBF}$ and penicillin/streptomycin, and were stored at $37{ }^{\circ} \mathrm{C}$ and $5 \% \mathrm{CO}_{2}$ for $24 \mathrm{~h}$ for the active products of the intracanal medication could release through the culture medium, producing eluates $[8,15]$.

\subsection{Parameters for Laser Irradiation}

Laser irradiation was performed by a Twin-laser device (MMOptics ${ }^{\mathrm{TM}}$, Equipamentos Ltda., São Carlos, São Paulo, Brazil). The device was registered at the Brazilian National Health Surveillance Agency (ANVISA) under \# 80051420007 and certified by the Brazilian Institute of Metrology, Standardization, and Industrial Quality (INMETRO) under \# NCC 2756/05. The plates were irradiated $1 \mathrm{~h}$ after wells contacting eluates, and again with a 6-hour interval [16]. Table 2 describes irradiation parameters.

The desired application per well was $3 \mathrm{~J} / \mathrm{cm}^{2}$. It was standardized the design of experiments and developed a laser-adapted support for placing the plates to be irradiated. Knowing that the distance between the laser and the application surface is crucial, the distance between the laser beam and the cells was standardized. It was intercalated the wells to avoid energy overload due to the spreading characteristics of laser irradiation. A dark mask made of perforated matte cardboard was placed on the plate according to the location of wells, exposure only the area to be irradiated. After laser irradiations, the plates were incubated again at $37^{\circ} \mathrm{C}$ in humid atmosphere with $5 \% \mathrm{CO}_{2}$ [16].

\subsection{Cytotoxicity Test}

Human pulp fibroblasts (FP6) were cultivated in DMEM (LGC Biotecnologia, Cotia, Brazil) supplemented with 10\% SBF (Invitrogen, New York, USA) at $37{ }^{\circ} \mathrm{C}$ and $5 \% \mathrm{CO}_{2}$. Therefore, $8 \times 10^{3}$ cells were cultivated with $4 \mathrm{~mL}$ of cell medium for $24 \mathrm{~h}$ at $37{ }^{\circ} \mathrm{C}$ in atmosphere of $5 \% \mathrm{CO}_{2}$, in plates of 96 wells (Prolab, São Paulo, SP, Brazil). The culture medium present in the wells of the plates where fibroblasts adhered was removed and added $200 \mu \mathrm{L}$ of the eluate of medication tested to each well. After, the eluates were removed and added $100 \mu \mathrm{L}$ of MTT (3-(4,5-dimethylthiazol-2-il)-2,5-diphenyltetrazolium bromide) (Life Technologies, Carlsbad, USA) reagent solution, in each experimental 

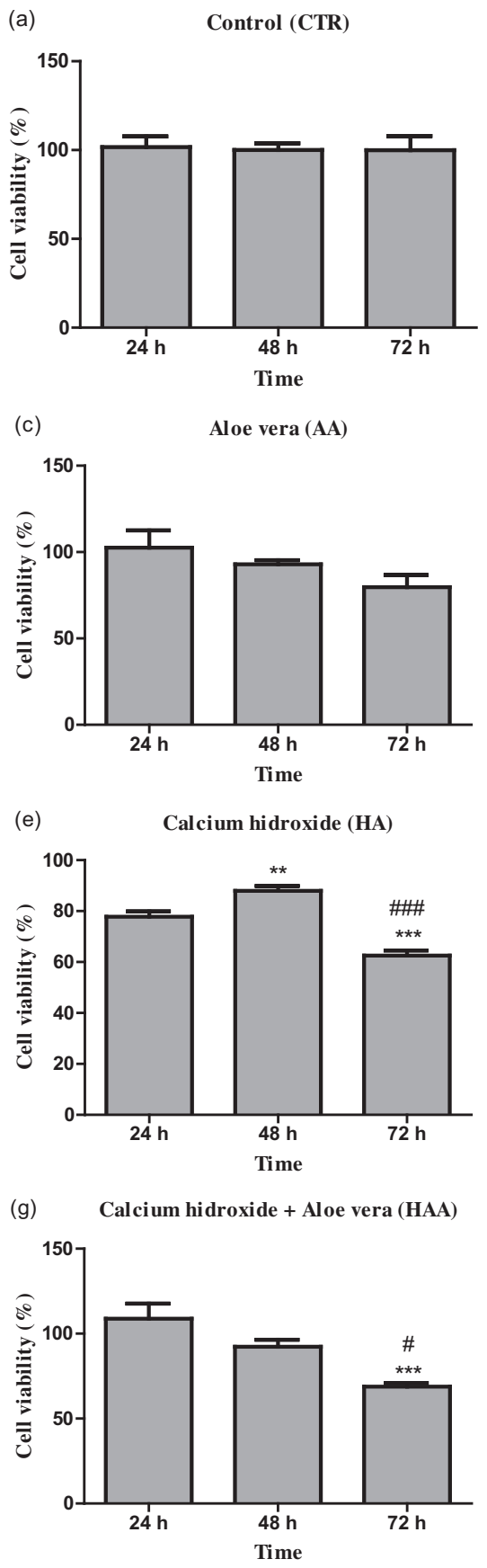

(b) Control + laser therapy (CL)

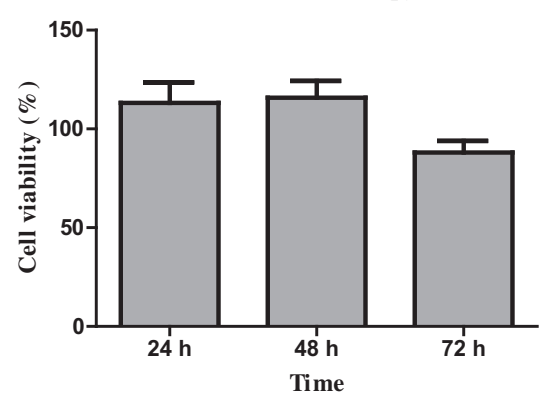

(d) Aloe vera + laser therapy (AL)

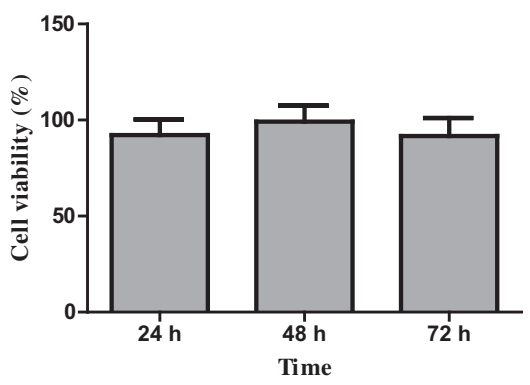

(f) Calcium hydroxide + laser therapy (HL)

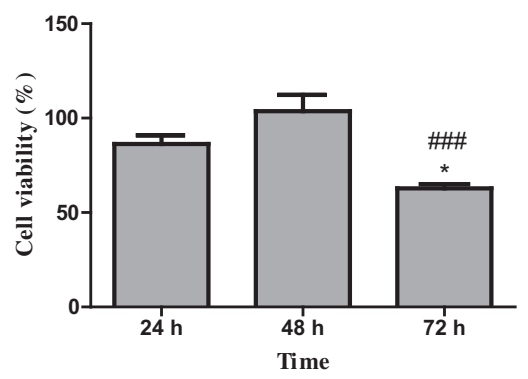

(h) Calcium hydroxide + Aloe vera + laser therapy (HAL)

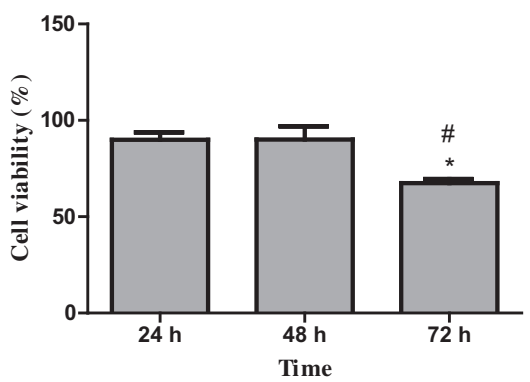

Fig. 1. Determination of percentage of cell viability of each group in relation to the control group at $24 \mathrm{~h}, 48 \mathrm{~h}$ and $72 \mathrm{~h}$. Data expressed as mean \pm mean standard deviation. ${ }^{*} \mathrm{p}<0.05$, * $p<0.01$, and ${ }^{* * *} p<0.001$, significantly different from $24 \mathrm{~h}$; \# p $<0.05$, \#\# $\mathrm{p}<0.01$, and \#\#\# $\mathrm{p}<0.001$ significantly different from $48 \mathrm{~h}$ (ANOVA and Tukey's post-hoc test). period and the plates were incubated for $1 \mathrm{~h}$. Then, the MTT solution was removed and added DMSO (Dimethyl Sulfoxide) for $10 \mathrm{~min}$. The optical density of culture plates was measured in the spectrophotometer (Cambrex ELx808cse) at 570-nm wavelength, obtaining data by Gen5 Data Analysis Software (BioTek U.S. - World Headquarters, USA), with 10-s agitation protocol followed by the reading.

\subsection{Genotoxicity Test}

Genotoxicity was evaluated by the micronucleus test (FluoroShield with DAPI). For this, the human pulp fibroblasts (FP6) $\left(2 \times 10^{4}\right)$ were cultivated with $1 \mathrm{~mL}$ of DMEM supplemented with $10 \%$ SBF for $24 \mathrm{~h}$ at $37{ }^{\circ} \mathrm{C}$ in atmosphere of $5 \% \mathrm{CO}_{2}$, in plates of 24 wells (Prolab, São Paulo, SP, Brazil). Cells were exposed to eluates for $24 \mathrm{~h}$, according to experimental groups. Next, the supernatant was discarded and performed washes with buffered saline solution (free from calcium and magnesium
PBS-CMF) for removing non-viable cells. Then, the cells were fixed with $10 \%$ formaldehyde for $10 \mathrm{~min}$. After washing, it was added $200 \mu \mathrm{L}$ of PBS and a drop of FluoroShield with DAPI. The plate was agitated in orbital table (Solab, Piracicaba, São Paulo, Brazil) for 5 min under light protection. The micronuclei were analyzed in fluorescence microscope $(100 \times)$, with potential assessment of 2.000 cells/plate per concentration, in at least three independent experiments.

\subsection{Statistical Analysis}

Cytotoxicity was measured by adding the absolute values of optical density obtained in the spectrophotometer and by calculating the mean of intracanal medications at each experimental period. The genotoxicity analysis was performed by fluorescence microscopy counting only mononucleate cells presenting micronuclei, mitosis and apoptotic cells. Data obtained in both tests were statistically analyzed by ANOVA 
$24 \mathrm{~h}$

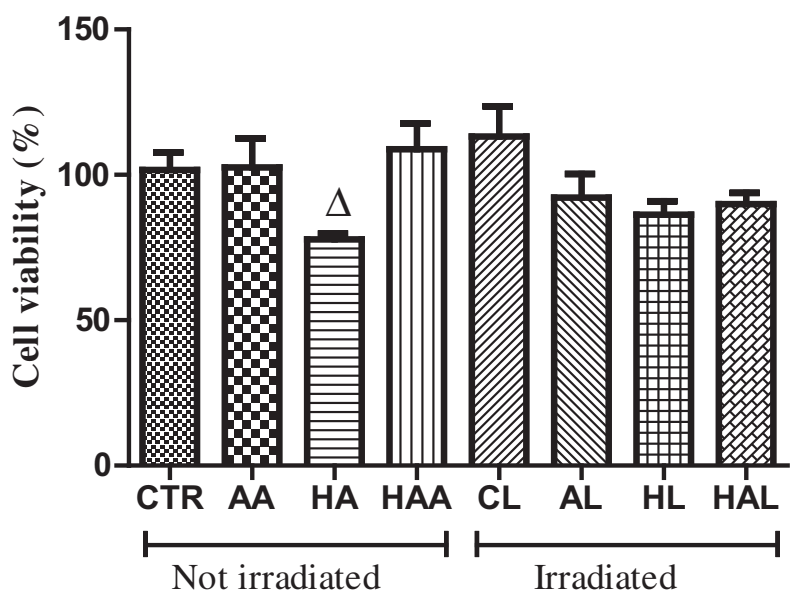

$48 \mathrm{~h}$

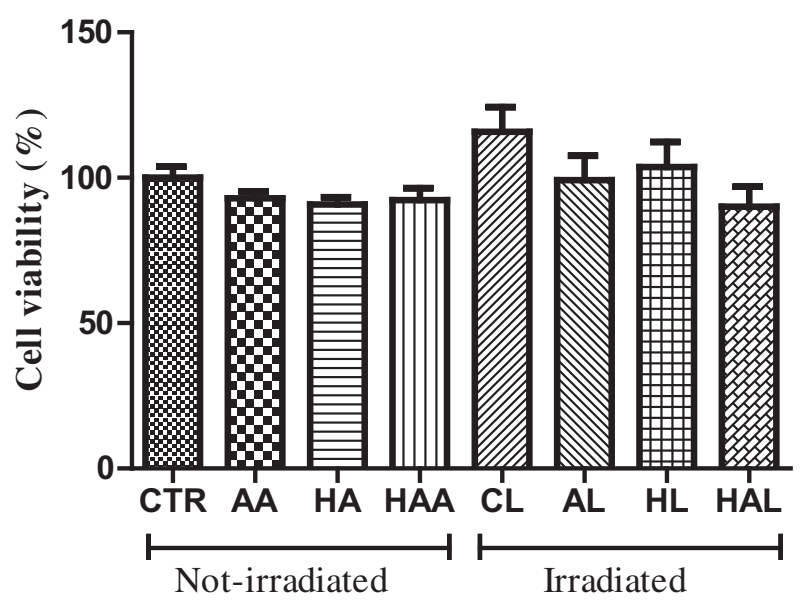

$72 \mathrm{~h}$

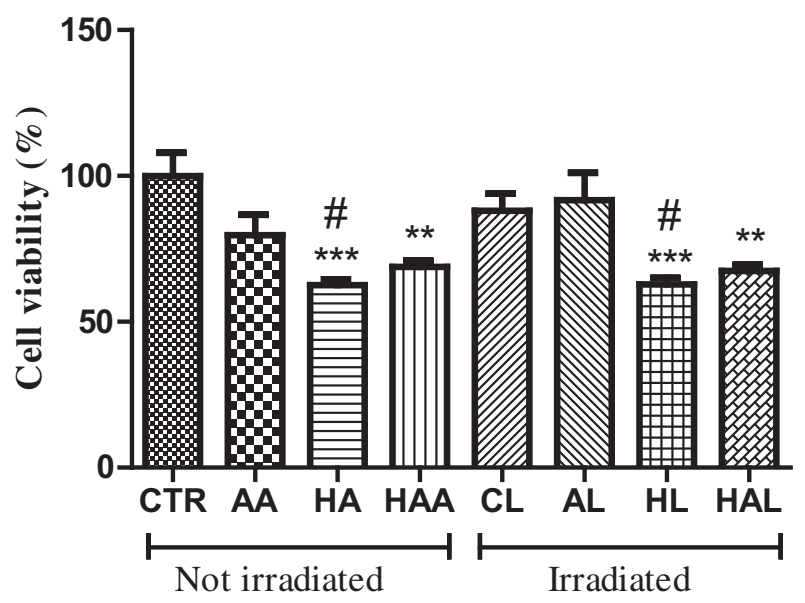

Fig. 2. Determination of percentage of cell viability relative to the mean of the control group after 24, 48, and $72 \mathrm{~h}$. Data expressed as mean \pm mean standard deviation. $\Delta p<0.05$, significantly different from CL; *** $p<0.001$, and $* * p<0.01$, significantly different from CTR; \# $\mathrm{p}<0.05$, significantly different from AL (ANOVA and Tukey's post-hoc test). complemented by Tukey's test, at $5 \%$ significance ( $p \leq 0.05$ ), with the statistical software GraphPad Prism 5.0.

\section{Results}

The cytotoxicity results, by means of the percentage of cell viability, are shown in Fig. 1. All tested medications showed different cell viability depending on experimental period. At $48 \mathrm{~h}$, calcium hydroxide (HA) increased cell viability compared to $24 \mathrm{~h}(p<0.01)$, and considerably decreased it at $72 \mathrm{~h}$ compared to $24 \mathrm{~h}$ and $48 \mathrm{~h}(p<0.001)$ (Fig. 1-e).

At $72 \mathrm{~h}$, group HAA decreased cell viability in relation to $48 \mathrm{~h}$ $(p<0.05)$ and presented significantly reduce compared to $24 \mathrm{~h}$ $(p<0.001$ ) (Fig. 1-g). The FTL in groups HL and HAL showed a considerable difference between $48 \mathrm{~h}$ and $72 \mathrm{~h}(\mathrm{p}<0.001$ and $p<0.05$, respectively), and both groups decreased cell viability after $24 \mathrm{~h}(p<0.05)$ (Fig. 1-f and h).

The group treated with laser alone (CL) had the highest cell survival rate at $24 \mathrm{~h}$, with mean of $113.13 \%$. The calcium hydroxide (HA) presented the lowest cell survival rate at $24 \mathrm{~h}(77.81 \%)$ with significant difference only from group CL $(p<0.05)$. The laser alone group (CL) showed higher cell survival rate at $48 \mathrm{~h}$, with mean of $115.85 \%$ of cell viability. After $48 \mathrm{~h}$, the group HAL showed the lowest cell viability, with $90.07 \%$ (Fig. 2).

The group treated with Aloe vera and FTL (AL) showed higher cell survival rate at $72 \mathrm{~h}$, with mean of $91.71 \%$ and statistical difference from groups HA and HL $(p<0.05)$. Group HL showed the lowest cell survival rate at $72 \mathrm{~h}$, with mean of $62.56 \%$ and significant difference from the control group (CTR) $(p<0.001)$. At $72 \mathrm{~h}$, groups HA and HL showed significant statistical difference ( $<<0.001$ ) from CTR (Fig. 2).

The Aloe vera with FTL (AL) stimulated higher cell division, followed by CL, HAL e HA. Regarding to the micronucleus test, group AL presented higher genotoxicity and significant results compared to group CTR $(p<0.001)$. Similarly, group CL showed high genotoxicity, followed by groups HAA and AA. Group HL exhibited low genotoxicity compared to AL $(p<0.001)$. The number of apoptotic cells was higher in groups AA and HAL. However, the other groups presented a slightly higher mean than CTR, except for group HAA, which showed lower number of apoptotic cells (Figs. 3 and 4).

\section{Discussion}

This research presented that using FTL decreased cell viability in the association with Aloe vera and standard endodontic medication. However, FTL stimulated higher cell proliferation when used alone and associated with only one intracanal medication. Laser irradiation had no influence in the genotoxicity of Aloe vera and calcium hydroxide association. Groups HAA and HAL presented low micronucleus formation, showing that FTL did not interfere with the genotoxicity of the combined medications. However, we found that the presence of Aloe vera increased gene mutation compared to isolated calcium hydroxide, achieving a lower biocompatibility index.

In this study, the pulp fibroblasts were chosen once they grow easily and fast, and are located in areas susceptible to the effects of intracanal medications and their degradation products, as periapical tissues and periodontal ligaments. Also, these cells are the main producers of collagen tissue and therefore actively participate in the tissue repair process $[17,18]$.

Calcium hydroxide is the gold-standard material for the treatment of root canals, which feature antimicrobial activity, mechanical blockage to avoid canal reinfection, limitation of root resorption, induction of mineralized tissue, and promotion of periapical and adjacent tissue repair $[9,19]$ with secondary anti-inflammatory action. This intracanal medication presented no genotoxicity but showed cytotoxicity, also observed in other studies $[20,21]$; however, some authors disagree with these findings $[22,23]$. This inconsonance may be related to the 

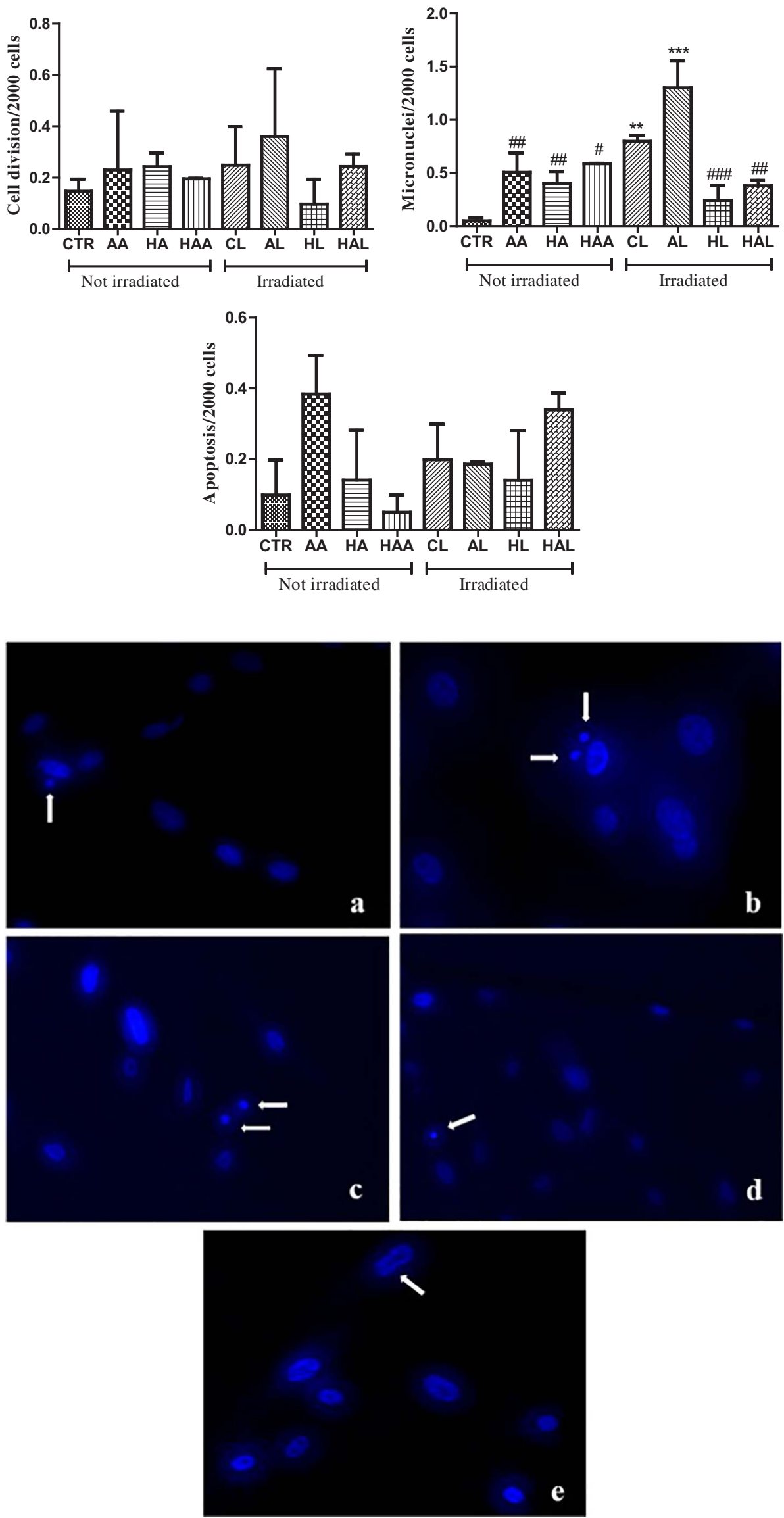

Fig. 4. a, b: Image of micronuclei in fluorescence microscope at $100 \times$ magnification, at $24 \mathrm{~h}$; c, d: Image of cells with nuclear fragmentation by apoptosis in fluorescence microscope at $100 \times$ magnification, at $24 \mathrm{~h}$; e: Image of cell division in fluorescence microscope at $100 \times$ magnification, at $24 \mathrm{~h}$.
Fig. 3. Determination of the mean number of consistent changes with genotoxicity in the different groups, after $4 \mathrm{~h}$. Data expressed as mean \pm mean standard error. *** $p<0.001$, and ${ }^{* *} p<0.01$, significantly different from CTR; \#\#\# $\mathrm{p}<0.001$, \#\# $\mathrm{p}<0.01$, and \# $p<0.05$, significantly different from AL (ANOVA and Tukey's posthoc test). 
different protocols among researches, such as the rate between the surface area of specimens and the volume of culture medium defined by the ISO 10993-5:2009 [14], which varies from 0.5-6.0 $\mathrm{cm}^{2} / \mathrm{mL}$.

The direct action of calcium hydroxide in the cell promotes physical and chemical changes, glycoprotein cleavage, protein denaturation, and formation of necrosis areas with fast crystal precipitation, causing calcium and phosphorus ion depositions [24], as well as the formation of coagulation necrosis foci of dystrophic calcification in subcutaneous tissues of rats [25].

As for Aloe vera, it stimulates healing through antibodies production and removes free radicals produced by neutrophils. Different from steroids, the anti-inflammatory properties of this plant block inflammation and stimulate fibroblast growth, accelerating the healing process [26]. It stands out that the seeding area and the form of cultivating the plant may change its chemical composition. Acemannan is the main polysaccharide extracted from the Aloe vera gel and can promote cell proliferation of dental pulp and differentiation and mineralization of the extracellular matrix $[27,28]$.

In this study, Aloe vera showed low cytotoxicity, probably because of the presence of catalase enzyme, which converts antioxidant hydrogen peroxide $\left(\mathrm{H}_{2} \mathrm{O}_{2}\right)$ into water and oxygen, suppressing the generation of these free radicals and improving cell efficacy and conservation, as well as hindering lipid peroxidation, in agreement with Fox et al. [29]. Thus, the presence of Aloe vera antioxidants is necessary to inhibit the generation of free radicals, minimizing cell damages [30]. However, this plant increased the frequency of genetic changes in fibroblasts, expressing chromosome damages by micronuclei formation [31]. These micronuclei are major genotoxicity biomarkers, considering they are fragments of genetic material separated from the nucleus, formed over the telophase of mitosis or meiosis because of chromosome damages suffered by the exposure to external agents [32].

In another in vitro experiment, concentrations from 2 to $16 \mathrm{mg} / \mathrm{mL}$ of acemannan significantly increased the proliferation of gingival fibroblasts and stimulated the secretion of keratinocytes-1 growth factor (KGF-1) and vascular endothelial growth factor (VEGF), as well as typeI collagen. All these substances have a direct connection to healing once they play important roles such as tissue re-epithelialization, formation of blood vessels and connective tissue [28].

According to previous studies regard to FTL, Loevschall et al. [33] showed that the energy density with stimulant effects in the synthesis of deoxyribonucleic acid (DNA) increased fibroblast proliferation [33,34]. Moreover, the ISO 10993-5:2009 [14] instructs that the parameter of laser irradiation used is related to the visible wavelength, which is absorbed by mitochondria photoreceptors, resulting in photochemical effects that trigger a cascade of metabolic events and finally result in biomodulation [35].

Interaction with FTL showed a tendency to increase cell viability after the experimental periods of 24 and $48 \mathrm{~h}$ in groups CL and HL, probably because it increased ATP concentration, stimulating fibroblast proliferation and consequently releasing cell growth factors (PDGF, IGF-I, TGF) [36]. However, there was a low cell viability at $72 \mathrm{~h}$, which shows an increase of cytotoxicity throughout time, considering that laser application in the first hours of the experiment. Nevertheless, group HL and CL presented the lowest and highest genotoxicity, respectively.

Aloe vera (AA) presented high genotoxicity and its association with FTL (AL) increased even more. The calcium hydroxide present in group HAA promoted high cytotoxicity, especially at $72 \mathrm{~h}$, maybe because of its solubility and increase of $\mathrm{pH}$ promote enzyme denaturation and cell membrane destruction, leading to cell death [24]; however, it showed no genotoxicity.

The associations of Aloe vera with FTL aim to facilitate the use of calcium hydroxide, to enable ion diffusion through dentinal tubules, and to improve its biocompatibility [37]. However, it is clear that the natural environment presents several intrinsic factors in the root canal system, which an in vitro study may not reproduce, such as temperature, inflammatory exudate, several pathogens, necrosis cells, and the response of each organism. Therefore, an in vivo study is required to gather more data for including a new intracanal medication in endodontic treatment.

However, our research points to the relevance of using an appropriate cell line to study the cytotoxicity and genotoxicity of endodontic materials, since the clinical use of intracanal medications involves direct contact with the pulp and periradicular tissues.

In addition, we emphasize the importance of an intracanal medication with active and viscous vehicle, conferred by the mucilaginous properties of Aloe vera. In this way, the beneficial qualities of this plant, when associated with calcium hydroxide or FTL, may improve apical and periapical repair, once Aloe vera allowed higher cell viability in human pulp fibroblasts.

\section{Conclusions}

The association of Aloe vera with calcium hydroxide or FTL promoted higher cell viability in human pulp fibroblasts, but the genotoxicity increased. However, calcium hydroxide presented high cytotoxicity for pulp fibroblasts, and FTL alone showed higher cell proliferation. Therefore, Aloe vera could be an alternative for association with intracanal medication or FTL during the endodontic therapy.

\section{Acknowledgements}

The authors would like to thank FAPITEC/SE (Research and Technological Innovation Support Foundation of the State of Sergipe) and CAPES (Coordination and Improvement of Higher Level or Education Personnel).

\section{References}

[1] M. Torabinejad, D. Kutsenko, T.K. Machnick, A. Ismail, C.W. Newton, Levels of evidence for the outcome of nonsurgical endodontic treatment, J. Endod 31 (9) (2005) 637-646 https://doi.org/10.1097/01.don.0000153593.64951.14.

[2] O.V. Pablo, R. Estevez, C. Heilborn, N. Cohenca, Root anatomy and canal configuration of the permanent mandibular first molar: clinical implications and recommendations, Quintessence Int. 43 (1) (2012) 15-27.

[3] R.K.P. Lima, J.M. Guerreiro-Tanomaru, N.B. Faria-Junior, M. Tanomaru-Filho, Effectiveness of calcium hydroxide-based intracanal medicaments against Enterococcus faecalis, Int. Endod. J. 45 (4) (2012) 311-316 https://doi.org/10. 1111/j.1365-2591.2011.01976.x.

[4] R. Ordinola-Zapata, C.M. Bramante, P.G. Minotti, B.C. Cavenago, R.B. Garcia, N. Bernardineli, et al., Antimicrobial activity of triantibiotic paste, $2 \%$ chlorhexidine gel, and calcium hydroxide on an intraoral-infected dentin biofilm model, J. Endod. 39 (1) (2013) 115-118 https://doi.org/10.1016/j.joen.2012.10.004.

[5] H.P. Lopes, J.F. Siqueira Jr., Endodontics: Biology and Technique, third ed., Guanabara Koogan, Rio de Janeiro, 2010.

[6] Y. Li, Biological properties of peroxide-containing tooth whiteners, Food Chem. Toxicol. 34 (9) (1996) 887-904 https://doi.org/10.1016/S0278-6915[96)00044-0.

[7] D.A. Ribeiro, M.M. Sugui, M.A. Matsumoto, M.A. Duarte, M.E. Marques, D.M. Salvadori, Genotoxicity and cytotoxicity of mineral trioxide aggregate and regular and white Portland cements on Chinese hamster ovary [CHO] cells in vitro, Oral Surg. Oral Med. Oral Pathol. Oral Radiol. Endod. 101 (2) (2006) 258-261 https://doi.org/10.1016/j.tripleo.2005.02.080.

[8] S.E.A. Camargo, C.H.R. Camargo, K.-A. Hiller, S.M. Rode, H. Schweikl, G. Schmalz, Cytotoxicity and genotoxicity of pulp capping materials in two cell lines, Int. Endod. J. 42 (3) (2009) 227-237 https://doi.org/10.1111/j.1365-2591.2008.01506.x.

[9] M.E. Vianna, D.M. Zilio, C.C. Ferraz, A.A. Zaia, F.J.de Souza-Filho, B.P. Gomes, Concentration of hydrogen ions in several calcium hydroxide pastes over different periods of time, Braz. Dent. J. 20 (5) (2009) 382-388 https://doi.org/10.1590/ S0103-64402009000500005.

[10] Z.Z. Xu, L. Zhang, T. Liu, J.Y. Park, T. Berta, R. Yang, et al., Resolvins RvE1 and RvD1 attenuate inflammatory pain via central and peripheral actions, Nat. Med. 16 (5) (2010) 592-597 https://doi.org/10.1038/nm.2123.

[11] K. Mizutani, Y. Musya, K. Wakae, T. Kobayashi, M. Tobe, K. Taira, et al., A clinical study on serum prostaglandin E2 with low-level laser therapy, Photomed. Laser Surg. 22 (6) (2004) 537-539 https://doi.org/10.1089/pho.2004.22.537.

[12] N. Kiliç, The effect of Aloe vera gel on experimentally induced peritoneal adhesions in rats, Revue Méd. Vet. 156 (7) (2005) 409-413.

[13] A.S. Semenoff, A.F. Bosco, D. Maia, R.V. Ribeiro, E.B. Aguiar, G.E.G.D. Rocatto, et al., The influence of Aloe vera and propolis in the contraction of wounds on dorsal area of rats, R Periodontia 17 (1) (2007) 5-10.

[14] International Organization for Standardization, ISO 10993-5: Biological Evaluation 
of Medical Devices - Tests for in Vitro Cytotoxicity, Suiça, 34 (2009).

[15] C.V. Bin, M.C. Valera, S.E. Camargo, S.B. Rabelo, G.O. Silva, I. Balducci, et al., Cytotoxicity and genotoxicity of root canal sealers based on mineral trioxide aggregate, J. Endod. 38 (4) (2012) 495-500 https://doi.org/10.1016/j.joen.2011.11. 003.

[16] N.A. Pereira, C.D.P. Eduardo, E. Matson, M.M. Marques, Effect of low-power laser irradiation on cell growth and procollagen synthesis of cultured fibroblasts, Lasers Surg. Med. 31 (4) (2002) 263-267 https://doi.org/10.1002/lsm.10107.

[17] P. Yoshino, C.K. Nishiyama, K. Cristina, C.F. Santos, C.R. Sipert, In vitro cytotoxicity of white MTA, MTA Fillapex ${ }^{\mathrm{TM}}$ and Portland cement on human periodontal ligament fibroblasts, Braz. Dent. J. 24 (2) (2013) 111-116 https://doi.org/10.1590/01036440201302115.

[18] M. de P. Farias, F. des. Matos, N.C. Carvalho, R.P. de Almeida, A.A.M. de Mendonça, R.L.C. de Albuquerque Júnior, et al., Assessment of intracanal medications cytotoxicity on L929 fibroblast cells, Biosci. J. 32 (2) (2016) 566-573 http://dx.doi.org/ 10.14393/BJ-v32n2a2016-30974.

[19] M.A. Duarte, A.C. Demarchi, M.H. Giaxa, M.C. Kuga, S.C. Fraga, L.C. de Souza, Evaluation of $\mathrm{pH}$ and calcium ion release of three root canal sealers, J. Endod. 26 (7) (2000) 389-390.

[20] S.V. Barbosa, C.M.S. Barroso, P.A. Ruiz, Cytotoxicity of endodontic irrigants containing calcium hydroxide and sodium lauryl sulphate on fibroblasts derived from mouse L929 cell line, Braz. Dent. J. 20 (2) (2009) 118-121 https://doi.org/10. 1590/S0103-64402009000200005.

[21] M. Guigand, P. Pellen-Mussi, A. Le Goff, J.M. Vulcain, M. Bonnaure-Mallet, Evaluation of the cytocompatibility of three endodontic materials, J. Endod. 25 (6) (1999) 419-423.

[22] G.T.B. Correa, G.A.C. Veranio, L.E. Silva, R. Hirata Junior, J.M. Coil, M.F.Z. Scelza, Cytotoxicity evaluation of two root canal sealers and a commercial calcium hydroxide paste on THP1 cell line by trypan blue assay, J. Appl. Oral Sci. 17 (5) (2009) 457-461 https://doi.org/10.1590/S1678-77572009000500020.

[23] N.B. Ruparel, F.B. Teixeira, C.C.R. Ferraz, A. Diogenes, Direct effect of intracanal medicaments on survival of stem cells of the apical papilla, J. Endod. 38 (10) (2012) 1372-1375 https://doi.org/10.1016/j.joen.2012.06.018.

[24] A.M. de Queiroz, S. Assed, M.R. Leonardo, P. Nelson-Filho, L.A.B. da Silva, MTA and calcium hydroxide for pulp capping, J. Appl. Oral Sci. 13 (2) (2005) 126-130 https://doi.org/10.1590/S1678-77572005000200006.

[25] P.J.S. Tomaz, M.P. Farias, M.R. Piva, R.L.C. Albuquerque Júnior, M.A.G. Ribeiro, Effect of laser therapy in inflamed tissue by medications based on iodoform laser therapy in inflamed tissue, Am. J. Appl. Oral Sci. 10 (1) (2013) 81-88 https://doi org/10.3844/ajassp.2013.81.88.

[26] C.C. Faleiro, S.T.H. Elias, L.C. Cavalcanti, A.S.S. Cavalcanti, The extract of medicinal aloe leaves, Aloe vera, on the healing of experimental wounds in the rat skin, A
Plcebo Controlled Essay, Nat on Line 7 (2), 2009, pp. 56-60.

[27] N. Jittapiromsak, D. Sahawat, W. Banlunara, P. Sangvanich, P. Thunyakitpisal, Acemannan, an extracted product from Aloe vera, stimulates dental pulp cell proliferation, differentiation, mineralization, and dentin formation, Tissue Eng. Part A 16 (6) (2010) 1997-2006 https://doi.org/10.1089/ten.TEA.2009.0593.

[28] S. Jettanacheawchankit, S. Sasithanasate, P. Sangvanich, W. Banlunara, P. Thunyakitpisal, Acemannan stimulates gingival fibroblast proliferation; expressions of keratinocyte growth factor-1, vascular endothelial growth factor, and type collagen; and wound healing, J. Pharmacol. Sci. 109 (4) (2009) 525-531 https:// doi.org/10.1254/jphs.08204FP.

[29] L.T. Fox, A. Mazumder, A. Dwivedi, M. Gerber, D. du Plessis, J.H. Hamman, In vitro wound healing and cytotoxic activity of the gel and whole-leaf materials from selected aloe species, J. Ethnopharmacol. 200 (2017) 1-7 https://doi.org/10.1016/j. jep.2017.02.017.

[30] F. Punit, B. Sudhindra, T. Nilima, P. Debaprya, Evaluation of Aloe vera gel as a storage medium in maintaining the viability of periodontal ligament cells - an in vitro study, J. Clin. Pediatr. Dent. Winter 40 (1) (2016) 49-52 http://dx.doi.org/10. 17796/1053-4628-40.1.49.

[31] M. Fenech, Important variables that influence base-line micronucleus frequency in cytokinesis-blocked lymphocytes-a biomarker for DNA damage in human populations, Mutat. Res. Genet. Toxicol. Environ. Mutagen. 404 (1-2) (1998) 155-165 https://doi.org/10.1016/S0027-5107(98)00109-2.

[32] R.P. Araldi, T.C de Melo, T.B. Mendes, P. de Sá Júnior, B.H.N. Nozima, E.T. Ito, et al., Using the comet and micronucleus assays for genotoxicity studies: a review, Biomed Pharmacother 72 (2015) 74-82 https://doi.org/10.1016/j.biopha.2015.04. 004.

[33] H. Loevschall, D. Arenholt-Bindslev, Effect of low-level diode laser irradiation of human oral mucosa fibroblasts in vitro, Lasers Surg. Med. 14 (4) (1994) 347-354.

[34] F.G. Basso, T.N. Pansani, A.P.S. Turrioni, V.S. Bagnato, J. Heblin, C. De.S Costa, In vitro wound healing improvement by low-level laser therapy application in cultured gingival fibroblasts, Int. J. Dent. 2012 (2012) 6 ID 719452 https://doi.org/10 $1155 / 2012 / 719452$.

[35] N. Gutknecht, C.P. Eduardo, Dentistry and Laser: Laser Action in an Odontological Specialty, Quintessence, São Paulo, 2004.

[36] L. Almeida-Lopes, J. Rigau, R.A. Zângaro, J. Guidugli-Neto, M.M. Jaeger, Comparison of the low level laser therapy effects on cultured human gingival fibroblasts proliferation using different irradiance and same fluence, Lasers Surg. Med. 29 (2) (2001) 179-184.

[37] V.E.deS. Batista, D.D. Olian, G.G. Mori, Diffusion of hydroxyl ions from calcium hydroxide and Aloe vera pastes, Braz. Dent. J. 25 (3) (2014) 212-216 https://doi. org/10.1590/0103-6440201300021. 